be no doubt that it is only by moving, so to speak, along the plane of the teachers' minds that the experimenter can hope to convince them.

(d) How shall we mark arithmetical problems so as to get a system of fairly accurate units? I hare used a systein which calls each rational step one unit. Mr. Locke suggests that the marks should increase as the square of the number of steps. It is probable that neither method is quite satisfactory. Both methods are doubtless true in the sense that they may be quite relevant to particular purposes; but the difficulties of the problems are not entirely dependent on the number of steps, but also on the sequence and interdependence of the steps. The most satisfactory method is the weighing of the problems according to the actual performances of children who have been untaught, who have received as much instruction in one form of problem as in another.

I trust that these few remarks may be found relevant to the discussion of the questions raised by Mr. Locke. I can assure him that I fully realize both the difficulty and the importance of the issues to which he has called attention.

W. H. Wrincer.

London, England.

\title{
TESTS FOR CLASS PURPOSES AND FOR RESEARCH PUIRPOSES.
}

Recent experience in testing the mental imagery of a class in elementary psychology suggested the desirability of a few remarks on the above heading. The tests given in Betts' "The Distribution and Functions of Mental Imagery," pp. 20-24, were most used, and with great success for teaching purposes. The writer is convinced that time spent by elementary students in the laboratory practice of observing and grading inages is well spent. At least half the time spent on the subject of imagination may well be spent in such interesting and enlightening introspections. The questions are admirably adapted to call forth and give opportunity for observing the different kinds and degrees of imagery.

Their unsuitability for certain other purposes, however, came out very clearly when the results of the introspections were compared with the results of another experiment. The images were graded $a$ when they seemed to be as vivid or clear as a perception, and $b, c, d$ 
and $e$ for lower degrees of vividness, the last meaning no images. The following values were given to the grades: $a=4, b=3, c=2$, $d=1, e=0$, and compatation made that permitted a comparison of these arbitrary units of vividness of the different types of imagery. The result gave the following order: First, cutaneous; second, kinesthetic; third, olfactory; fourth, gustatory ; fifth, auditory; sixth, visual; seventh, organic. This was very astonishing to those who had taken the test and who had supposed that the visual images were most vivid and the auditory next, instead of both being nearly at the bottom of the list.

Another experiment had been given before these results were announced in which such words as the following were spoken: Drum, mutton, piano, sugar, wind, and the students wrote the names of the images aroused in the order in which they came, and marked with a plus sign the kind of image that was most vivid. It was found that over half of the words aroused visual images first, and that they were the most vivid in nearly the same proportion of cases. It is evident that the words nsed gave in every case good opportunity for forming other than visual images. This confirms in a striking way the common belief that visual images are much more numerous and vivid than any other.

Why, then, did the other test indicate, as it also did when Betts used it, that visual images are not so vivid as the other kinds? An examination of Betts' questions reveals the fact that they are admirably suited to eroke every possible image of each kind. An inspection of the questions, however, shows that the greater possibilities of visual imagery are recognized in the questions themselves, and hence that we cannot expect superiority to be shown upon comparing the resulting figures. This may be illustrated by questions 17-20. The first question of this series calls for the vividness of the image of a familiar landscape as a whole. This is a question of the same type as all of the questions designed to evoke cutaneous imagery, which, according to the results of this test, are most vivid. In the case of visual imagery, however, the greater possibilities of analytic and detailed imagery are recognized by asking, in addition to the exact location of particular objects, the size and shape of particular objects and differences in sharpness of detail between near and distant objects. Regarding most forms of imagery other than visual, it would be impossible to formulate such detailed, analytic questions as the abore. 
That the viridness dejends largely upon the nature of the questions, which in general favor other senses more than the visual, is indicated by the fact that the per cent. of vivid images varies but little for the twenty questions regarding cutaneous imagery, while in the visual group there are great differences. For example, question 5, as to the color of tablecloth and napkins, is marked as $a$ in degree of vividness by 93 students, whereas the different shades and tints in sky and clouds are marked $a$ by only 29 .

It is evident from the above that the tests are admirably suited to give students laboratory practice in forming and observing the different kinds of images which they can call up, and that they are correspondingly unsuited for a research upon the comparative vividness of the different kinds of images. It is probable that these questions will be used by many teachers of psychology; hence it is important that attention should be called to the points mentioned above in order that wrong impressions may not be given to students.

Although it is doubtless true, as Hetts says, that beginners overestimate the vividness of their images, yet it is interesting to find that almost at once they can grade their images with some confidence in their own judgments. Rarely do normal students hesitate as to how to grade the images eroked into one of five classes. It may be that this is because they actually have more vivid images than more mature people, and not simply because they overestimate the vividness of their mental states.

It was found that after a very little practice they could also mark the image with an $m$ or an $f$ to indicate whether the image was free or involved memory of a specific experience. It was found that organic and olfactory images that were vivid were more likely to involve memories, while a larger proportion of the vivid visual images were free images. Inspection of answers to special questions indicated that viridness of imagery often involved memory of rare, intense or recent experiences, but that oft-repeated perceptions, such as the color of the tablecloth, gave vivid but free images. Individual differences as to whether images are free or memory images differ greatly. With some, memories are nearly always involved, while with others images that are almost wholly free are common. A study, along this line, of persons of different ages wonld doubtless give interesting results.

E. A. KiRK PATRICK.

Fitchburg, Mass. 